九州大学学術情報リポジトリ

Kyushu University Institutional Repository

\title{
A Study on using Hot-rolled Steel Sheet for Ship Superstructure
}

Narimatsu, Hisao

TSUNEISHI SHIPBUILDING Co., Ltd.

Kuwada, Masakazu

TSUNEISHI SHIPBUILDING Co., Ltd.

Gotoh, Koj i

Kyushu University

ht tp://hdl. hand le. net/2324/4752586

出版情報: Proceedings of the 14th International Symposium, PRADS 2019, September 22-26, 2019， Yokohama, Japan- Volume III. 65, pp.243-257, 2020-10-04. Springer

バージョン：

権利関係 : 


\title{
A Study on using Hot-rolled Steel Sheet for Ship Superstructure
}

\author{
Hisao Narimatsu ${ }^{1}$, Masakazu Kuwada ${ }^{1}$ and Koji Gotoh ${ }^{2}$ \\ ${ }^{1}$ TSUNEISHI SHIPBUILDING Co., Ltd., \\ Numakuma-cho 1083, Fukuyama-city, Hiroshima, JAPAN \\ ${ }^{2}$ Kyushu University, Motooka 744, Nishi-ku 744, Fukuoka-city, Fukuoka, Japan \\ hisao.narimatsu@tsuneishi.com
}

\begin{abstract}
Application of the hot-rolled steel sheet for the members of superstructure, where the strength requirement of these parts in ships is not severe, is expected as a solution to reduce the hull construction cost. Because the hot-rolled steel sheet is applied after recoiling by cold working to return it to a flat plate, the material properties is deteriorated due to excessive plastic working and the residual stress induced by the plastic work might affect for the thermal cutting and welding. There is a possibility that the hot-rolled steel sheet has poor properties comparing with the flat rolled steels applied for hull parts where the structural integrities are required by the classification societies' rules. The difference of properties between the hot-rolled steel sheet and the flat rolled steel are investigated in this research. Investigated items are mechanical properties, microstructures, initial residual stress distributions, hardness distributions, distortion after thermal cutting and laser-arc hybrid welding.
\end{abstract}

Keywords: Hot-rolled Steel Sheet (Hot-coiled sheet), Residual stress, Deflection, Superstructure, Welding deformation.

\section{$1 \quad$ Introduction}

As one of the cost reductions in hull construction, there is an idea to use a hot-rolled steel sheet (as stated in the below, simply referred as hot-coiled sheet) which is relatively easy to procure in the production of a portion where the strength requirement is not severe such as accommodation blocks of ship superstructure. The hot-coiled sheet is shipped after rolled in a coil shaped form in steel mill manufacturers. After delivery to the factory, the hot-coil material is recoiled by cold machining and returned to flat plate shape for application of members in structures. Since the hot-coil material is processed into flat plate by plastic deformation, there is a concern that the material will deteriorate and that the material properties will be different from general flat rolled plate material (as stated in the below, simply referred as flat plate) at the time of thermal cutting and welding by the residual stress due to plastic work. The differences in the residual stress distributions and the difference in welding difficulty with the aim of 
application of the hot-coiled sheet to the hull superstructure are investigated in this study.

\section{Comparison of hot-coiled sheet and flat plate}

\subsection{Mechanical properties, chemical composition and microstructure}

Specimen shall be equivalent to Grade KA specified by ClassNK [1] were prepared in hot-coiled sheet and flat plate. According to consideration of variations in the material properties by steel mill manufacturers, materials were prepared from foreign manufacturers and from Japanese manufacturers which have enough experience of hull material approved by classification societies. Applied plate thickness in this study is $5.5 \mathrm{~mm}$ for all materials.

Mechanical properties, chemical composition and microstructure observation were carried to confirm the differences. The tensile test carried out with verified to Class NK rules [1]. Specimen shape U1 was applied. For chemical composition analysis, nitrogen was measured by the inert gas melting-TCD method. Oxygen was measured by the inert gas fusion and infrared absorption method. Other components was measured by the QV method from material surface. Microstructure observation was performed 100 and 400 times at the depth position of a quarter from the plate surface. Results of the tensile test, chemical composition measurements are shown in Tables 1 and 2, respectively. Photographs of the microstructural observation is shown in Fig.1.

Table 1. Mechanical properties of applied materials.

\begin{tabular}{|c|c|c|c|c|}
\hline Materials & $\begin{array}{c}\text { Yield stress } \\
(0.2 \% \text { Proof } \\
\text { stress }) \\
\left(\mathrm{N} / \mathrm{mm}^{2}\right)\end{array}$ & $\begin{array}{c}\text { Tensile } \\
\text { stress } \\
\left(\mathrm{N} / \mathrm{mm}^{2}\right)\end{array}$ & $\begin{array}{c}\text { Elongation } \\
(\%)\end{array}$ & $\begin{array}{c}\text { Yield ratio } \\
(\%)\end{array}$ \\
\hline $\begin{array}{c}\text { Hot-coiled sheet } \\
\text { (made Overseas) }\end{array}$ & $(308)$ & 430 & 22 & 72 \\
\hline $\begin{array}{c}\text { Flat plate } \\
\text { (made Overseas) }\end{array}$ & $(344)$ & 468 & 24 & 74 \\
\hline $\begin{array}{c}\text { Hot-coiled sheet } \\
\text { (made in Japan) }\end{array}$ & 366 & 480 & 24 & 76 \\
\hline $\begin{array}{c}\text { Flat plate } \\
\text { (made in Japan) }\end{array}$ & 356 & 445 & 29 & 80 \\
\hline
\end{tabular}


Table 2. Chemical composition of applied materials (unit in wt $\%$ ).

\begin{tabular}{|c|c|c|c|c|}
\hline \multirow{2}{*}{ Component } & \multicolumn{2}{|c|}{ Made overseas } & \multicolumn{2}{c|}{ Made in Japan } \\
\cline { 2 - 5 } & $\begin{array}{c}\text { Hot-Coiled } \\
\text { sheet }\end{array}$ & Flat plate & $\begin{array}{c}\text { Hot-Coiled } \\
\text { sheet }\end{array}$ & Flat plate \\
\hline $\mathrm{C}$ & 0.094 & 0.142 & 0.177 & 0.133 \\
\hline $\mathrm{Si}$ & 0.15 & 0.13 & 0.02 & 0.13 \\
\hline $\mathrm{Mn}$ & 0.86 & 0.82 & 0.62 & 0.64 \\
\hline $\mathrm{P}$ & 0.016 & 0.007 & 0.015 & 0.013 \\
\hline $\mathrm{S}$ & 0.007 & 0.003 & 0.006 & 0.005 \\
\hline $\mathrm{Cu}$ & 0.01 & 0.01 & 0.02 & 0.01 \\
\hline $\mathrm{Al}$ & 0.034 & 0.036 & 0.017 & 0.015 \\
\hline $\mathrm{Ni}$ & 0.01 & 0.01 & 0.01 & 0.01 \\
\hline $\mathrm{Cr}$ & 0.02 & 0.01 & 0.03 & 0.02 \\
\hline $\mathrm{Mo}$ & $<0.01$ & $<0.01$ & $<0.01$ & $<0.01$ \\
\hline $\mathrm{V}$ & 0.002 & 0.001 & 0.001 & 0.002 \\
\hline $\mathrm{Nb}$ & 0.002 & 0.001 & $<0.001$ & $<0.001$ \\
\hline $\mathrm{Ti}$ & $<0.001$ & 0.013 & $<0.001$ & $<0.001$ \\
\hline $\mathrm{B}$ & 0.0001 & 0.0001 & $<0.0001$ & $<0.0001$ \\
\hline $\mathrm{N}$ & 0.0023 & 0.0039 & 0.0025 & 0.0028 \\
\hline $\mathrm{O}$ & 0.0012 & 0.0013 & 0.0020 & 0.0013 \\
\hline & & & & \\
\hline
\end{tabular}

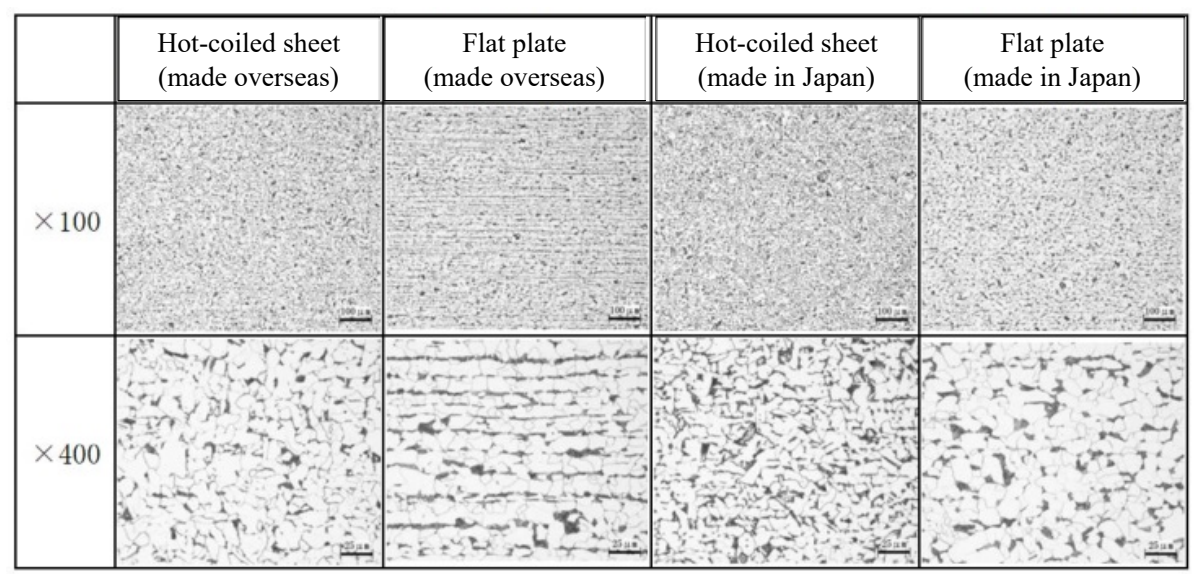

Fig. 1. Microscope observation.

On the steel plates made overseas, $0.2 \%$ proof stress was adopted because a clear yield point did not identified. Although the value of yield stress and tensile stress of hot-coiled sheet made overseas is lower than those made in Japan, all measured values 
of both materials satisfied the specification of Grade KA steel. Both microstructures are ferrite and pearlite. There is a slight difference in grain size and average grain diameter of hot-coil material made in japan is the finest. In the chemical composition, although the addition of a small amount of $\mathrm{Al}, \mathrm{Ti}$, etc. is observed in materials made overseas, it does not seem to have a significant influence on the difficulty for the thermal processing. The amount of $\mathrm{C}$ of hot-coil material made overseas is low. This difference might cause the difference in tensile strength between the hot-coil made in Japan and overseas.

\subsection{Residual stress and distribution of hardness}

Residual stress and Vickers hardness of each test materials are measured and compared by each processing method (hot-coil material and sheet material) and by manufacturers. The residual stress was measured using an X-ray diffraction method with $\cos \alpha$ method [2]. There is a concern that the properties of the hot-coil material might differ depending on the curvature in the coil winding condition (outer radius $980 \mathrm{~mm}$ ). Therefore, the steel sheets with shearing cut four sides in way that as much as refrained from thermal processing after rolling were prepared. Sample steel sheets with $1,800 \mathrm{~mm}$ wide and $3,500 \mathrm{~mm}$ long were picked up from the winding center side (outer radius $380 \mathrm{~mm}$ ) and the winding outer circumference side (outer radius $830 \mathrm{~mm}$ ). Figure 2 shows the shape of the sample steel plate and the residual stress measurement position. X-axis in Fig.2 corresponds to the rolling direction of the hot-coiled sheet and the flat plate. In these measurements, we ignored the front and back side of the plate due to thin specimen thickness.
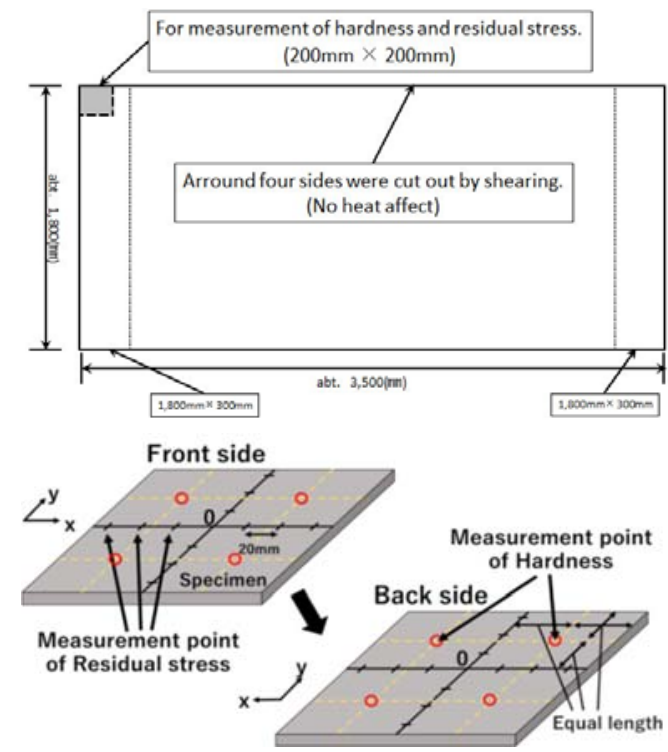

Fig. 2. Measured points of residual stress. 
Figure 3 shows measured compressive residual stress distributions on the front surface of the steel plate made overseas and Fig. 4 shows the result on the compressive residual stress on the front surface of the steel plate made in Japan.

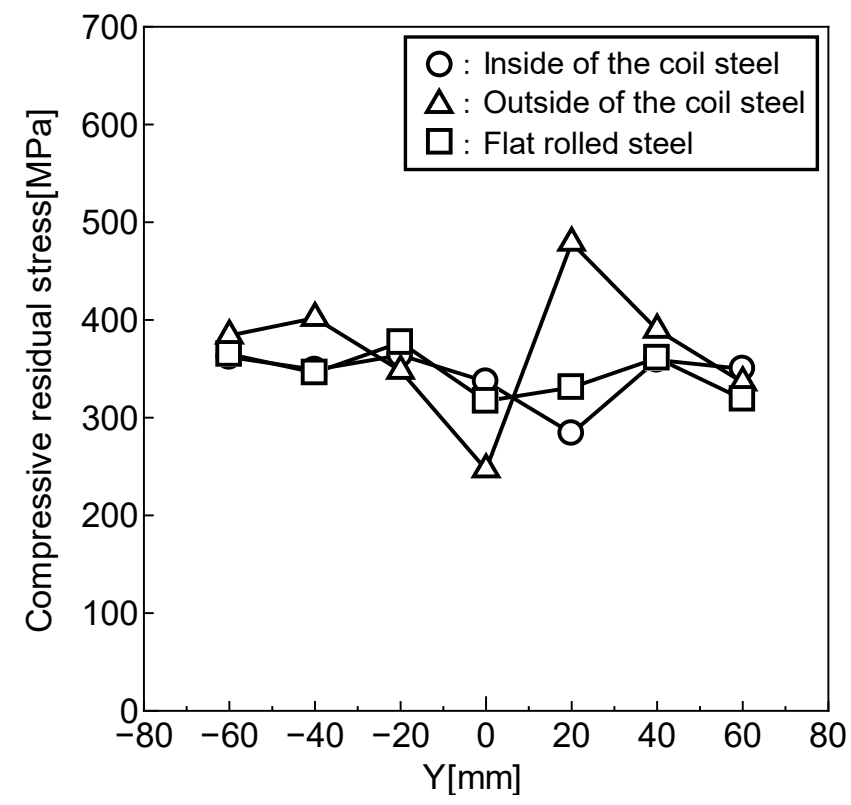

(a) Residual stress distribution of $x$ direction component along $y$ axis

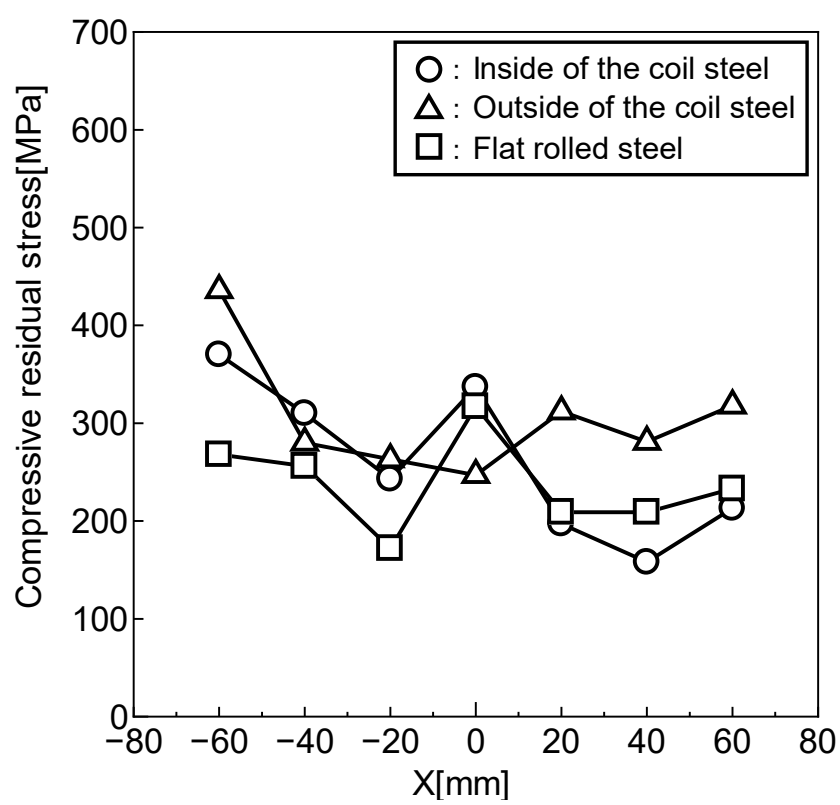

(b) Residual stress distribution of $x$ direction component along $x$ axis 


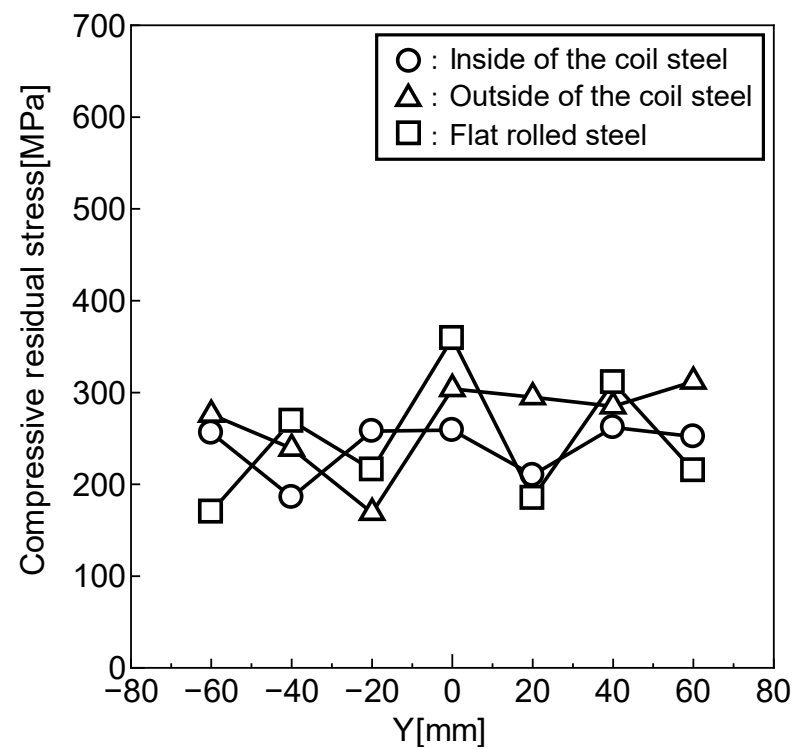

(c) Residual stress distribution of $y$ direction component along $y$ axis

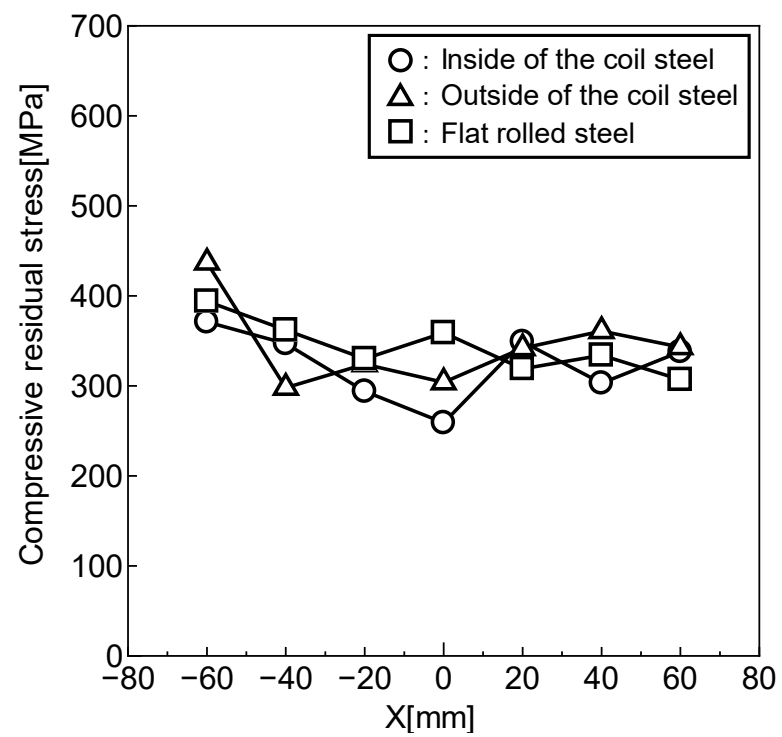

(d) Residual stress distribution of $y$ direction component along $x$ axis

Fig. 3. Comparison of residual stress on the front surface of steel for picking position. (Made overseas) 


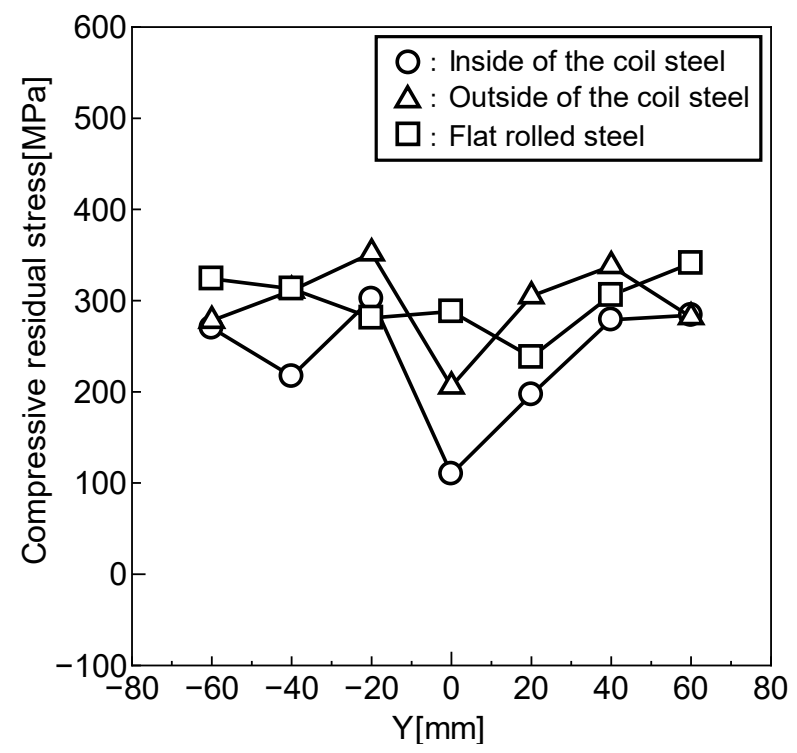

(a) Residual stress distribution of $x$ direction component along $y$ axis

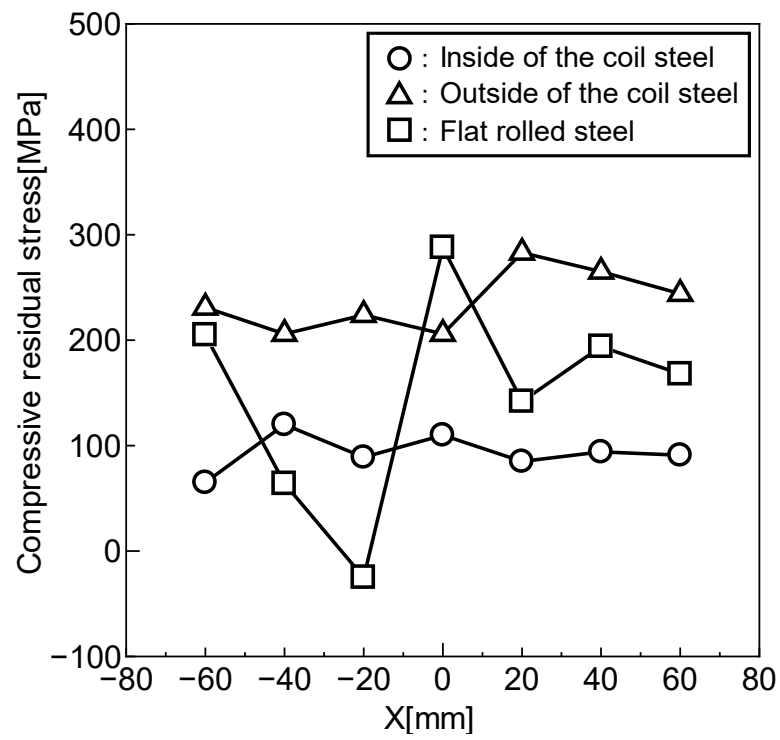

(b) Residual stress distribution of $x$ direction component along $x$ axis 


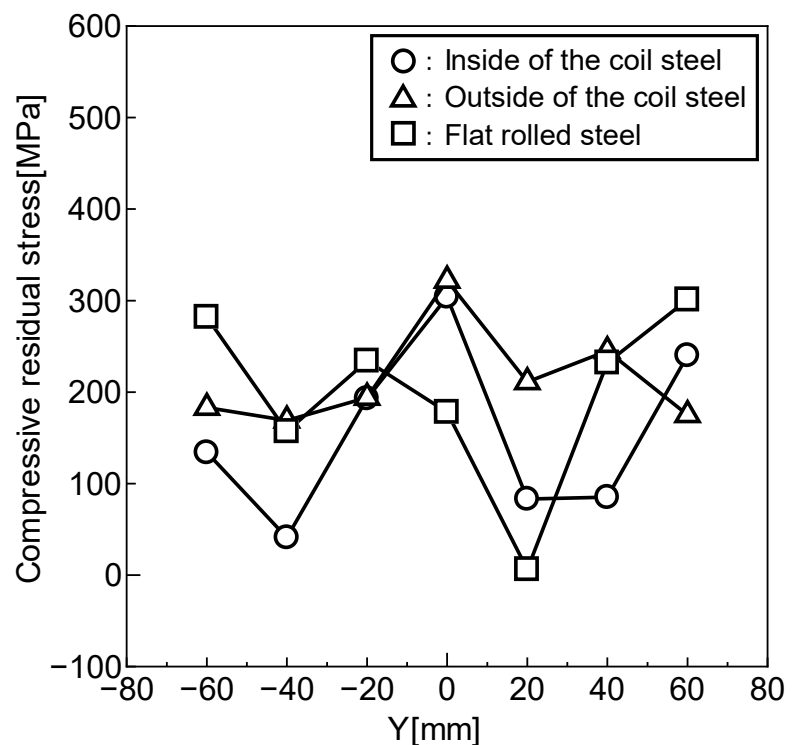

(c) Residual stress distribution of $y$ direction component along $y$ axis

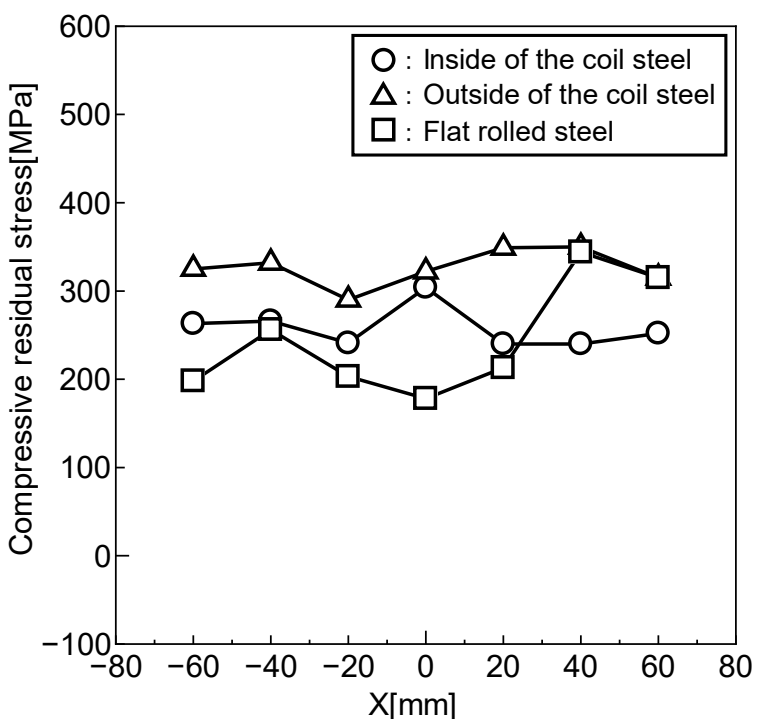

(d) Residual stress distribution of $y$ direction component along $x$ axis

Fig. 4. Comparison of residual stress on the front surface of steel for picking position. (Made in Japan)

From the measured result of the residual stresses, it is confirmed that the compression residual stress of hot-coiled sheet made in Japan is relatively smaller than one made overseas. No significant difference of residual stress distributions between hot- 
coiled sheet and flat plate in case of made overseas. In case of hot-coiled sheet made in Japan, the compressive residual stress of the sheet picked up outside the coil tends to be slightly higher than that picked up inner position.

Subsequently, Vickers hardness test using the test specimen used for residual stress measurement were performed. Table 3 shows the average values measured 4 points on each surface of the test specimen (measured position is red circle shown in Fig. 2). Materials made in Japan have smaller hardness value for flat plate than hot-coiled sheet, but there is no significant difference in materials made overseas.

Table 3. Comparison of Vickers hardness test results.

\begin{tabular}{|c|c|c|c|}
\hline \multicolumn{2}{|l|}{ Type of plate } & Front side & Back side \\
\hline \multirow{3}{*}{ Made in Japan } & Flat plate & 153 & 158 \\
\cline { 2 - 4 } & Hot-coiled sheet (inside) & 198 & 181 \\
\cline { 2 - 4 } & Hot-coiled sheet (outside) & 194 & 190 \\
\hline \multirow{3}{*}{ Made overseas } & Flat plate & 195 & 203 \\
\cline { 2 - 4 } & Hot-coiled sheet (inside) & 203 & 192 \\
\cline { 2 - 4 } & Hot-coiled sheet (outside) & 194 & 191 \\
\hline
\end{tabular}

\section{Deformation by thermal cutting}

\subsection{Verification of distortion by cutting}

Distortion caused by thermal fabrications might affect the appearance of the product, especially in thin sheet products. During the thin plate is thermally cut, the member is deformed due to the heat input effect, and in the case where the member is elongated, longitudinal deformation is often a serious problem due to cutting heat input. Since the hot-coiled sheet is affected by multiple plastic working for their recoiling process, there is concern that the appearance of deformation of the member due to thermal cutting might be different from that of the sheet material.

To compare and evaluate the deformation of each of hot-coiled sheet and flat plate by the cutting process, thermal cutting test was performed using plasma and laser cuttings to investigate the amount of deflection caused by the longitudinal deformation. Each specimen (dimensions: 1,800 wide and 3,500 mm long) was cut into a size of $280 \mathrm{~mm}$ wide and $880 \mathrm{~mm}$ long as shown in Fig. 5. The deflections were measured at the position shown in Fig. 6. 


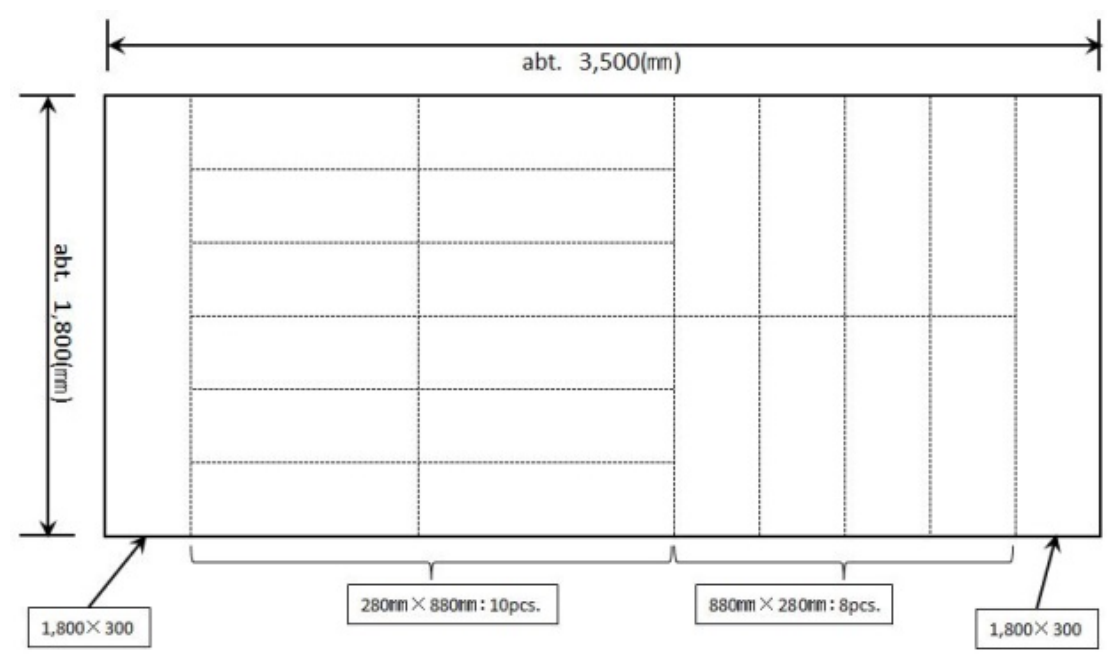

Fig. 5. Cutting plan.

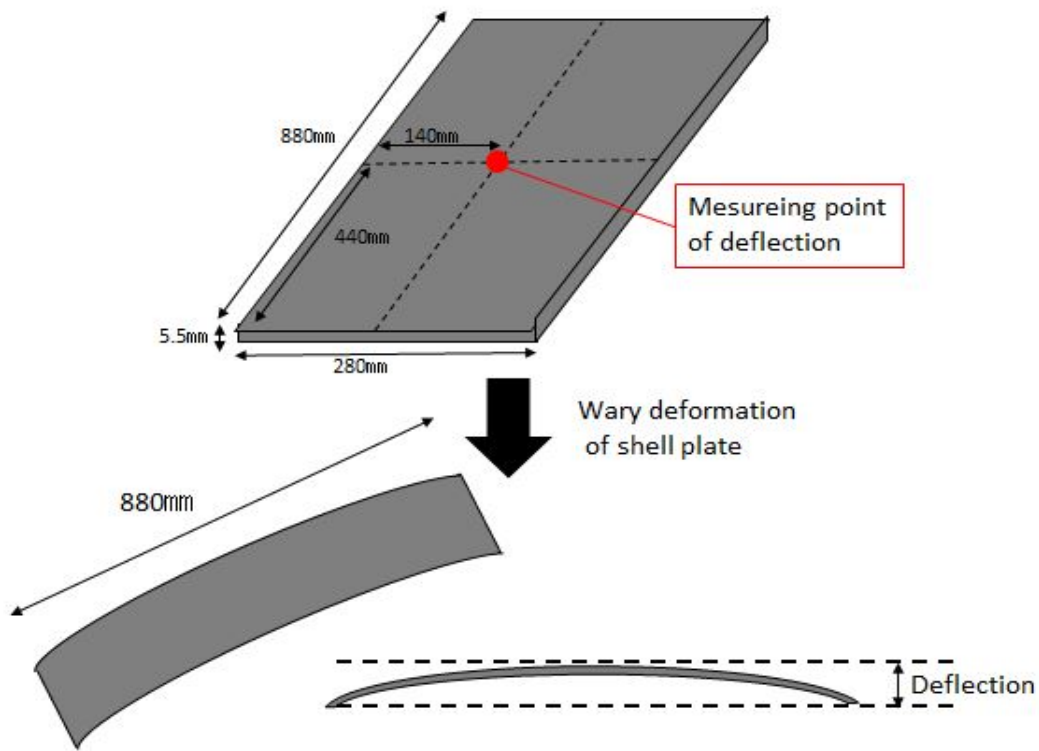

Fig. 6. Measured points of deflection.

\subsection{Measurement results and consideration}

Specimens were cut by plasma and laser cutting to 20 specimens (total 240 specimens) of $280 \mathrm{~mm}$ wide and $880 \mathrm{~mm}$ long per each material. Table 4 shows the average value of the longitudinal deflections at measured position shown in Fig. 6. 
Table 4. Measured deflection after cutting (unit in $\mathrm{mm}$ ).

\begin{tabular}{|c|c|c|c|}
\hline \multicolumn{2}{|c|}{ Type of plate } & Laser cutting & $\begin{array}{c}\text { Plasma cut- } \\
\text { ting }\end{array}$ \\
\hline \multirow{3}{*}{ Made in Japan } & Flat plate & 0.0 & 2.6 \\
\cline { 2 - 4 } & Hot-coiled sheet (inside) & 3.0 & 6.2 \\
\cline { 2 - 4 } & Hot-coiled sheet (outside) & 2.2 & 4.8 \\
\hline \multirow{3}{*}{ Made overseas } & Flat plate & 9.1 & 5.1 \\
\cline { 2 - 4 } & Hot-coiled sheet (inside) & 3.9 & 9.1 \\
\cline { 2 - 4 } & Hot-coiled sheet (outside) & 5.8 & 9.5 \\
\hline
\end{tabular}

It is confirmed except for the hot-coiled sheet made overseas that the longitudinal deflection in case of laser cutting is limited to about half of case of plasma cutting. Generally, it is the same tendency as the magnitude relation of general cutting deformation between laser and plasma cuttings. Moreover, it is confirmed that the amount of deflection is generally smaller for Japanese materials than for overseas materials. Especially when laser cutting was done on the hot-coiled sheet made in Japan, the deflection was almost at a negligible level. On the other hand, no significant difference was confirmed in comparison between inside and outside of the hot-coiled sheet. Referring these results, Considering these results, it is recommended to apply laser cutting to the cutting of thin plates used in superstructures.

\section{$4 \quad$ Evaluation of thermal deformation by welding}

\subsection{Verification of welding deformation by different cutting method}

To verify the difference in welding deformation between hot-coiled sheet and flat plate, the cut specimens by the plasma and laser cuttings obtained in the previous section was joined by the butt both-side submerged arc welding. Each the deflection before welding and after welding were measured. Welding conditions are shown in Table 5 and measurement positions of deflection are shown in Fig.7. The joint was manufactured by welding the longitudinal direction (except for the outer peripheral part) of two adjacent test pieces in Fig.5.

Table 5. Welding conditions of submerged arc welding.

\begin{tabular}{|c|c|}
\hline Travel speed (mm/min): & 600 \\
\hline Arc current (A): & 320 \\
\hline Arc voltage (V): & 30 \\
\hline Nominal heat input (J/mm): & 960 \\
\hline
\end{tabular}



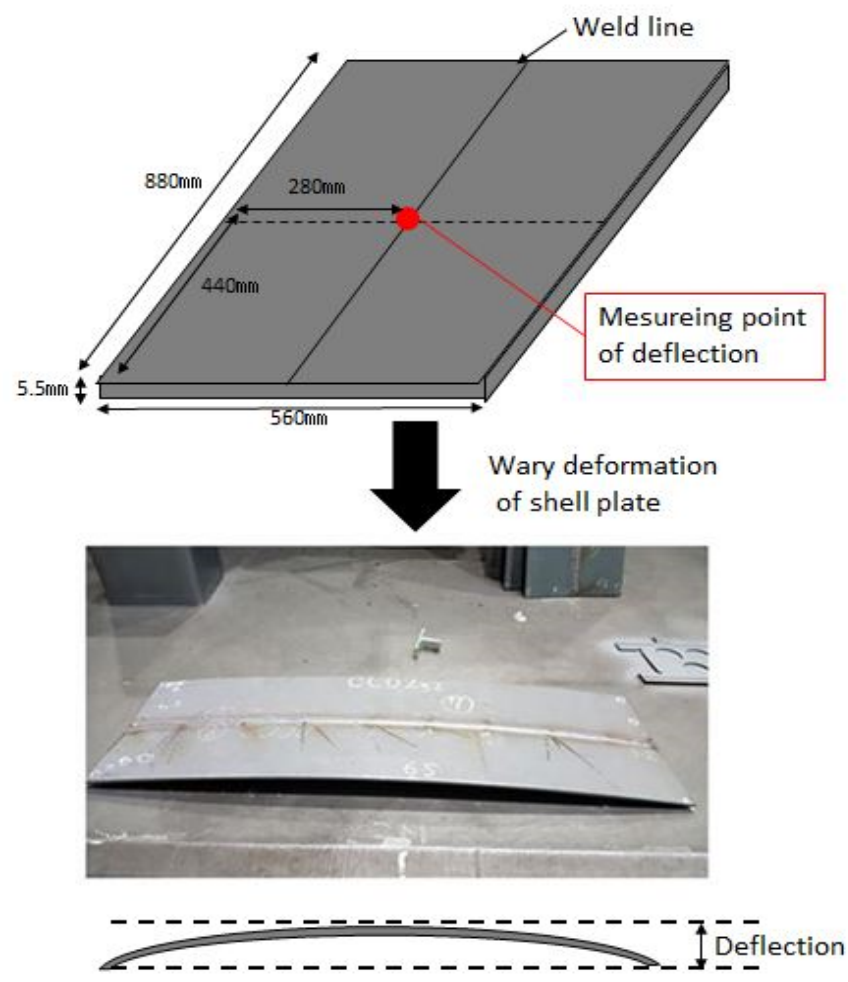

Fig. 7. Measured points of deflection.

Table 6 shows the measured value of the deflection of each specimen after welding. The values enclosed in parentheses in the table represent the difference between the amount of deflection before and after the welding by subtracting the deflection amount immediately after tack welding for the fitting.

Table 6. Measured deflection after welding (unit in $\mathrm{mm}$ ).

\begin{tabular}{|c|c|c|c|}
\hline \multicolumn{2}{|c|}{ Type of plate } & Laser cutting & Plasma cutting \\
\hline \multirow{3}{*}{ Made in Japan } & Flat plate & $16.0(16.0)^{*}$ & $18.0(15.5)^{*}$ \\
\cline { 2 - 4 } & Hot-coiled sheet (inside) & $19.8(16.8)^{*}$ & $28.3(22.1)^{*}$ \\
\cline { 2 - 4 } & Hot-coiled sheet (outside) & $22.0(19.9)^{*}$ & $29.5(24.7)^{*}$ \\
\hline \multirow{3}{*}{ Made overseas } & Flat plate & $20.3(11.2)^{*}$ & $24.0(18.9)^{*}$ \\
\cline { 2 - 4 } & Hot-coiled sheet (inside) & $23.8(19.9)^{*}$ & $27.3(18.2)^{*}$ \\
\cline { 2 - 4 } & Hot-coiled sheet (outside) & $18.3(12.5)^{*}$ & $26.5(17.0)^{*}$ \\
\hline
\end{tabular}

*Values of inside of bracket means difference from 'after cutting' to 'after welding'.

The total amount of deflection is smaller for the laser cut material than for the plasma cut material, since the amount of deflection before welding affect total deflection. Regarding the deformation due to welding, no significant difference was found in 
the relationship between the sheet and plate making process and the manufacturing method or the cutting method.

\subsection{Verification of welding deformation due to difference in welding heat input}

In the previous section, we confirmed that similar deflection is added as weld deformation regardless of steel type, when welding is applied to the steel sheet once subjected to the thermal cutting process. Therefore, we investigated the deflection before and after welding in the case of using a laser-arc hybrid welding method, which is a relatively low heat input welding method, to verify the possibility of reducing the amount of deformation. The measurement positions of the deflection are the same as in Fig.7. Table 7 shows the welding conditions for laser-arc hybrid welding, Fig. 8 shows the photographs of the welded specimens. Measured results are shown in Table 8.

Table 7. Welding conditions of laser-arc hybrid welding.

\begin{tabular}{|l|c|}
\hline Travel speed (mm/min): & 1600 \\
\hline Arc current (A): & 290 \\
\hline Arc voltage (V): & 26 \\
\hline Laser power (kW): & 4 \\
\hline Nominal heat input (J/mm): & 433 \\
\hline Distance between laser spot and center of arc (mm): & 5 \\
\hline Defocus distance (mm): & -5 \\
\hline Drag angle of arc torch (degree): & 40 \\
\hline Push angle of laser head (degree): & 10 \\
\hline Wire extension of arc welding $(\mathrm{mm}):$ & 20 \\
\hline Primer coating near weld line & Removed \\
\hline
\end{tabular}

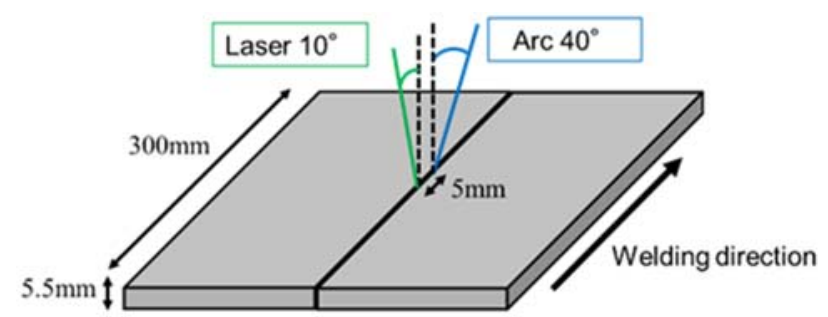




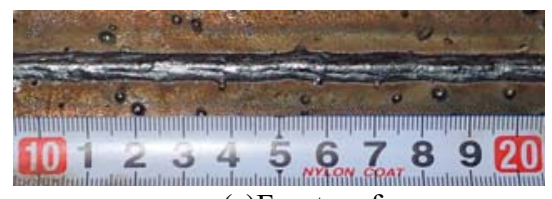

(a)Front surface

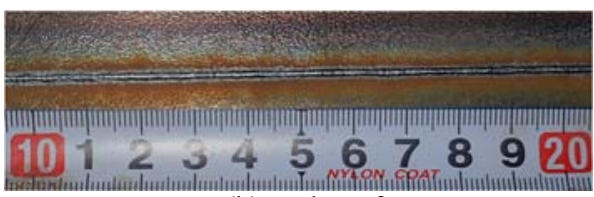

(b)Back surface

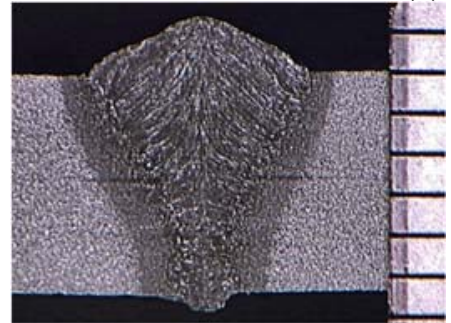

(c)Macroscopic observation

Fig. 8. Bead appearance and macroscopic observation.

Table 8. Measured deflection after welding (unit in $\mathrm{mm}$ ).

\begin{tabular}{|c|c|c|c|}
\hline \multicolumn{2}{|c|}{ Type of plate } & $\begin{array}{c}\text { Laser-arc hybrid } \\
\text { welding }\end{array}$ & $\begin{array}{c}\text { Submerged arc } \\
\text { welding }\end{array}$ \\
\hline \multirow{3}{*}{ Made in Japan } & Flat plate & (null) & 16.1 \\
\cline { 2 - 4 } & Hot-coiled sheet (inside) & 5.7 & 16.8 \\
\cline { 2 - 4 } & Hot-coiled sheet (outside) & 6.2 & 19.9 \\
\hline \multirow{3}{*}{ Made overseas } & Flat plate & (null) & 11.2 \\
\cline { 2 - 4 } & Hot-coiled sheet (inside) & 7.6 & 19.9 \\
\cline { 2 - 4 } & Hot-coiled sheet (outside) & (null) & 12.5 \\
\hline
\end{tabular}

Although the number of samples might be insufficient, measured results shown in Table 8 indicates that the welding deformation by hybrid welding is suppressed to about $1 / 3$ of submerged arc welding and it is expected that welding deformation occurring in the current shipbuilding work can be drastically reduced.

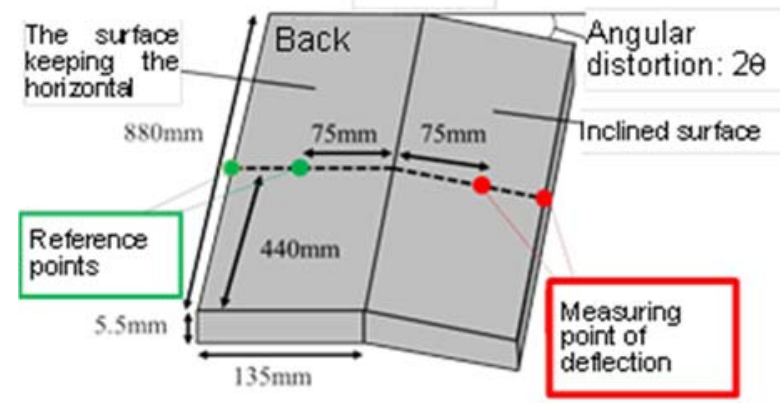

Fig. 9. Measured points for the angular distortion. 
The measurement positions of angular distortion are shown in Fig.9 Angular distortion was calculated by the displacement in the thickness direction between the two reference points and the two measuring points of deflection for the specimen immediately after temporary fitting by laser welding alone and the specimen after the main welding. The measurement results are shown in Table 9. The value of angular distortion of the flat plate tended to be smaller than that of the hot-coiled sheet from measured results. However, there was no significant difference in the degree of influence on the angular distortion in the hot-coiled sheet by the manufacturing country or the sampling position.

Table 9. Measured angular distortion.

\begin{tabular}{|c|c|c|}
\hline \multirow{2}{*}{ Type of plate } & $\begin{array}{c}\text { Angular distortion } \\
\text { (degree) }\end{array}$ \\
\hline \multirow{3}{*}{ Made in Japan } & Flat plate & 4.06 \\
\cline { 2 - 3 } & Hot-coiled sheet (inside) & 5.16 \\
\cline { 2 - 3 } & Hot-coiled sheet (outside) & 5.56 \\
\hline \multirow{3}{*}{ Made overseas } & Flat plate & 2.93 \\
\cline { 2 - 3 } & Hot-coiled sheet (inside) & 5.93 \\
\cline { 2 - 3 } & Hot-coiled sheet (outside) & 3.39 \\
\hline
\end{tabular}

\section{Conclusion}

From the viewpoint of the practical application of hot-coiled sheet to construct thin wall structures, the difference of the properties, initial residual stress distributions and the welding deformation of hot-coiled sheet and flat plate were investigated in this study.

It was confirmed that there was no serious difference regardless of hot-coiled sheet or flat plate, sampling location (inside or outside of the coil diameter) and orientation in the hot-coiled sheet, manufacturing country, etc. in case of using conventional shipbuilding methods such as plasma cutting and submerged arc welding. Therefore, the difference in material strength and weldability between the hot-coiled sheet and the flat plate is negligible.

On the other hand, it is confirmed that the application of low heat input construction methods such as laser cutting and laser-arc hybrid welding can decrease the deformation during the construction.

With regard to welding deformation reduction, it is important to carefully consider the balance between human costs and new equipment investment costs in the conventional manner to reduce the total construction cost.

\section{References}

1. Nippon Kaiji Kyokai (ClassNK): Rules for the survey and construction of steel ships (Part K Materials), (2018)

2. Pulstec Industrial Co., Ltd.: Portable X-ray Residual Stress Analyzer $\mu$-X360n, https://www.pulstec.co.jp/en/product/x-ray/ (accessed on March 15, 2019) 